\title{
Elemental diet in acute Crohn's disease
}

\author{
C Ó’MORÁIN, A M SEGAL, A J LEVI, AND H B VALMAN \\ Northwick Park Hospital and Clinical Research Centre, Harrow
}

SUMMARY Fifteen patients with acute Crohn's disease aged between 6 and 20 years were given an elemental diet. One patient received it by nasogastric tube and another would not tolerate it. All 14 patients have been reviewed for periods of between 1 and 3 years. An elemental diet appears to be a safe and effective method of inducing a remission in acute Crohn's disease.

Failure to gain weight and short stature are difficult to correct in children with Crohn's disease. Management of acute Crohn's disease may include corticosteroid therapy, ${ }^{1}$ sulphasalazine, ${ }^{1-3}$ or surgery. ${ }^{4-6}$ Corticosteroids may cause stunting of growth or vertebral collapse. Although surgery often results in a growth spurt, recurrence of active disease is common. ${ }^{7}$ Nutritional treatment in the form of total parenteral nutrition ${ }^{8-10}$ or special diets, ${ }^{11} 12$ or a combination of both, ${ }^{1314}$ has been effective in a few children. We have studied 14 young patients with Crohn's disease treated with an elemental diet which was given initially to induce a remission and later as a nutritional supplement.

\section{Patients and investigations}

The 15 patients were aged between 6 and 20 years and 10 of them, including the oldest, were prepubertal (Table). Six of 11 patients younger than 18 years were below the 3rd centile for weight and 2 were below the 3 rd centile for height. The diagnosis was suspected clinically and confirmed radiologically in each.

The disease was confined to the small bowel in 10 of the patients and in 5 both the small and large bowel were affected. Patients with small bowel disease had no abnormality detected by barium enema studies. In 5 the diagnosis was confirmed by biopsy, 3 by rectal and 2 by colonoscopy which showed granuloma formation, and in a further 2 by

Table Clinical details of patients treated with an elemental diet

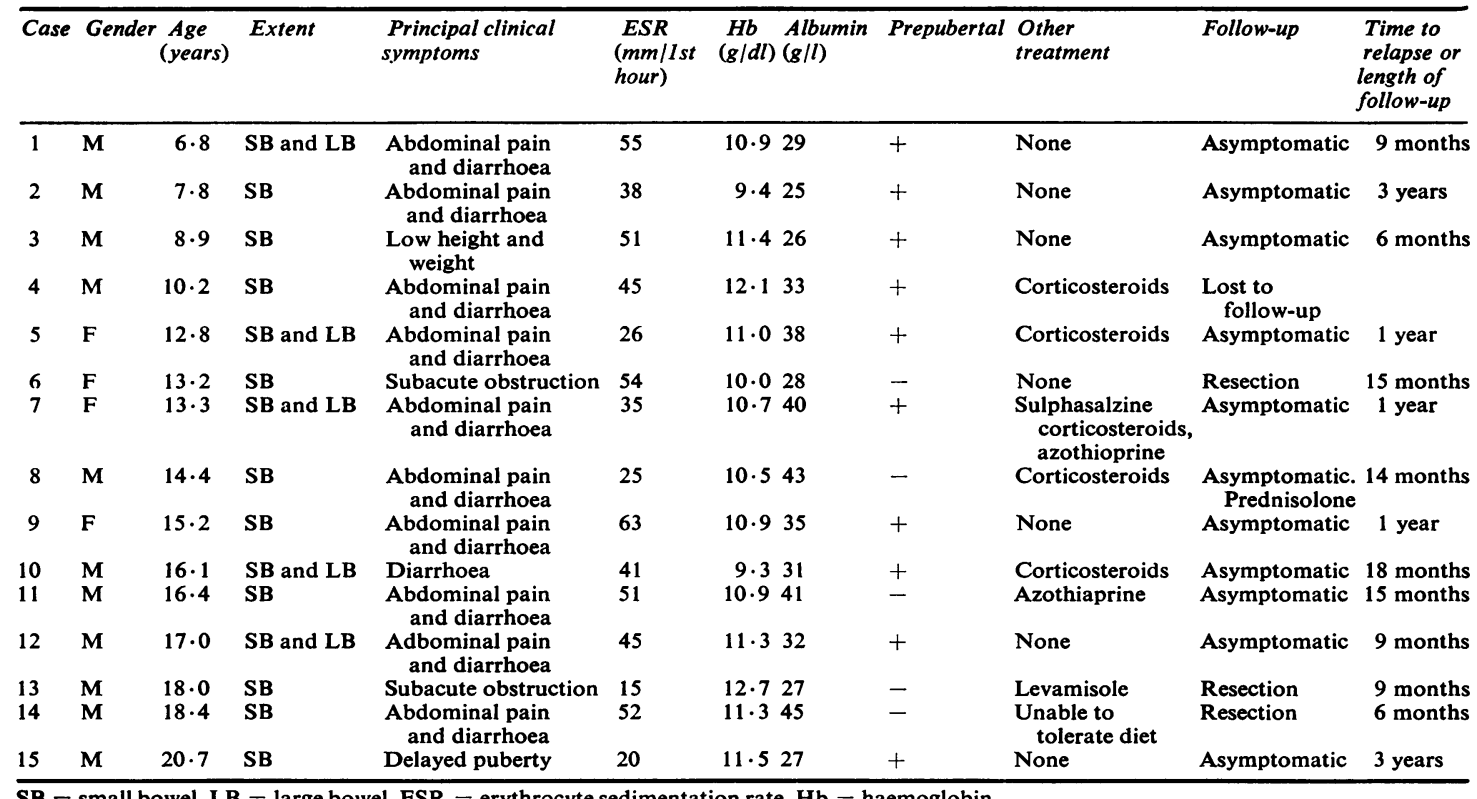


histology obtained at laparotomy. The red cell sedimentation rate was greater than $25 \mathrm{~mm}$ in the 1 st hour in 14 of the patients, 11 had serum albumin concentrations less than $35 \mathrm{~g} / \mathrm{l}$, and $12 \mathrm{had}$ haemoglobin levels less than $11.5 \mathrm{~g} / \mathrm{dl}$.

At least once a week patients were reviewed and blood taken for the estimation of red cell sedimentation rate, haemoglobin, and serum protein levels. Height and weight were recorded. Patients have been followed up for periods varying from 1 to 3 years except for one patient who failed to attend after 3 months. Three have subsequently needed intestinal resection and the remainder have had remissions lasting between 6 and 36 weeks.

\section{Treatment}

All food was stopped for 4 weeks and replaced by an elemental diet (Vivonex, Eaton Laboratories). The strength was increased from one-third of the recommended full strength during a period of 3 days. This introduction period was prolonged if the patient complained of bloating. The child received between 40 and $50 \mathrm{kcal} / \mathrm{kg}$ with a total 8-12 $\mathrm{g}$ of nitrogen a day. Specific food groups were reintroduced at weekly intervals to test for an allergen at the end of the treatment period. Fruit and vegetables were given for

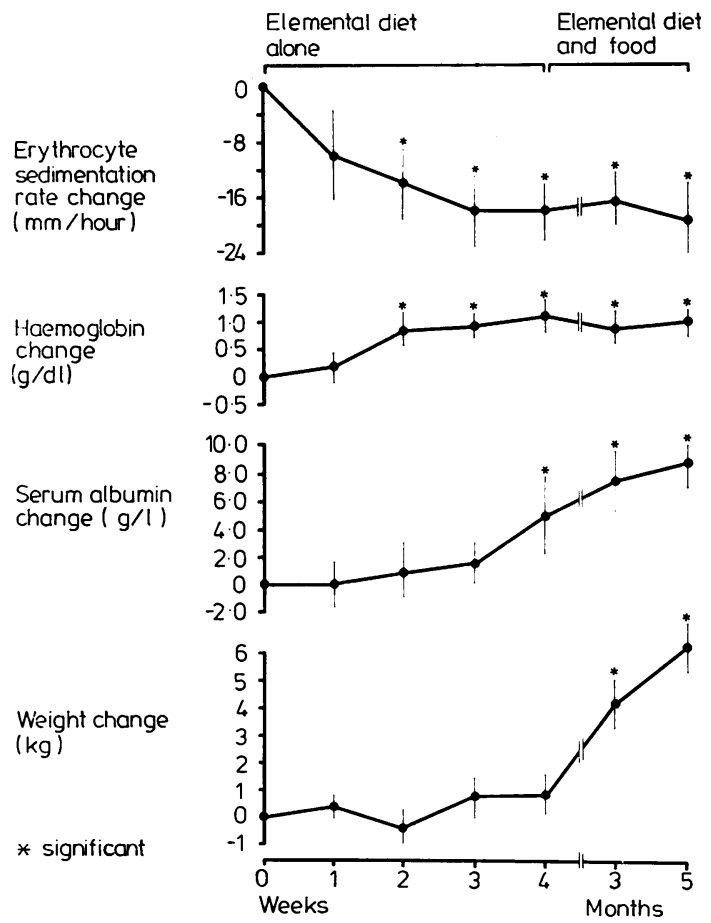

Fig. 1 Changes in various indices of disease activity of patients with Crohn's disease treated with an elemental diet. the first week and finally eggs and milk in the sixth week. During this period the elemental diet was the main source of nutrition. Some of the patients remained on the diet as a nutritional supplement for a longer period and received mineral supplements.

\section{Other treatment}

Five of the patients had received corticosteroids. Corticosteroids which failed to induce a remission in the same dosage were continued with the elemental diet in 3 patients. Another patient has a vertebral collapse as a side effect of treatment with corticosteroids before the elemental diet was started.

One patient received long-term levamisole which was used in an attempt to prolong remission, ${ }^{15}$ one was receiving azathioprine, and another was receiving corticosteroids, sulphasalazine, and azathioprine.

\section{Results}

Thirteen patients were able to tolerate the elemental diet orally, one received it by nasogastric tube and the other received corticosteroids as an alternative form of treatment. An improvement in symptoms occurred in all patients between 1 and 2 weeks after treatment started. This was accompanied by a fall in the red cell sedimentation rate, and a rise in the serum albumin and haemoglobin levels (Fig. 1).

Before the diet started all the patients showed poor growth. After 3 months of treatment 6 of the patients had crossed centiles for weight, 3 had crossed centiles for height, and the rest had not changed their weight centile (Fig. 2).

One patient with delayed puberty and short stature at age 19 years had Crohn's disease confined to the small gut. Treatment with corticosteroids and nutritional supplements had no effect. An elemental diet produced a striking increase in both height and weight (Fig. 3). Two of the other 3 patients (Cases 5 and 7), for whom corticosteroids failed to induce a remission, showed an improvement in height.

Two other patients (Cases 4 and 10) receiving the elemental diet were also given prednisolone (20 $\mathrm{mg} /$ day) but the diet was probably the reason that the prednisolone could be reduced quickly to $10 \mathrm{mg}$ on alternate days within 6 weeks.

We were unable to identify any specific food group that induced symptoms during the reintroduction of foods.

\section{Discussion}

The elemental diet appeared to play a major role in inducing a clinical remission in the 14 patients with Crohn's disease. The acute symptoms were controlled, growth improved, and puberty occurred. The reason for these changes is unknown. The elemental diet may provide nutrition in patients with 
malnutrition due to a poor intake of food as a result of anorexia and excessive protein loss from inflamed intestinal mucosa. Total parenteral nutrition either alone or in combination with oral feeding results in a 'growth spurt' in children with Crohn's disease. ${ }^{8-11}$ Similarly adults with Crohn's disease gain weight if given an elemental diet for a period up to a year. ${ }^{16}$ Four children with Crohn's disease had a significant height and weight gain when receiving continuous elemental diet as the only form of treatment. ${ }^{17}$

Another explanation for the effect of the elemental diet is that it contains no whole protein and therefore no allergens and may remove potential allergens from crossing the ulcerated bowel mucosa. A change $\equiv$ in the bowel microflora may be associated. The $\stackrel{0}{\rightarrow}$ elemental diet may also act as a medical by-pass as it reduces both gastric and pancreatic secretions ${ }^{18}$ and reduces faecal bulk as it contains no fibre. The increase in serum albumin observed in our patients may be attributed to the improvement in the nutritional status but could also be due to bowel rest. The recent findings of reduced gastrointestinal protein loss after an elemental diet lends support to this idea. ${ }^{19}$

The unpalatability of the diet is one of its main
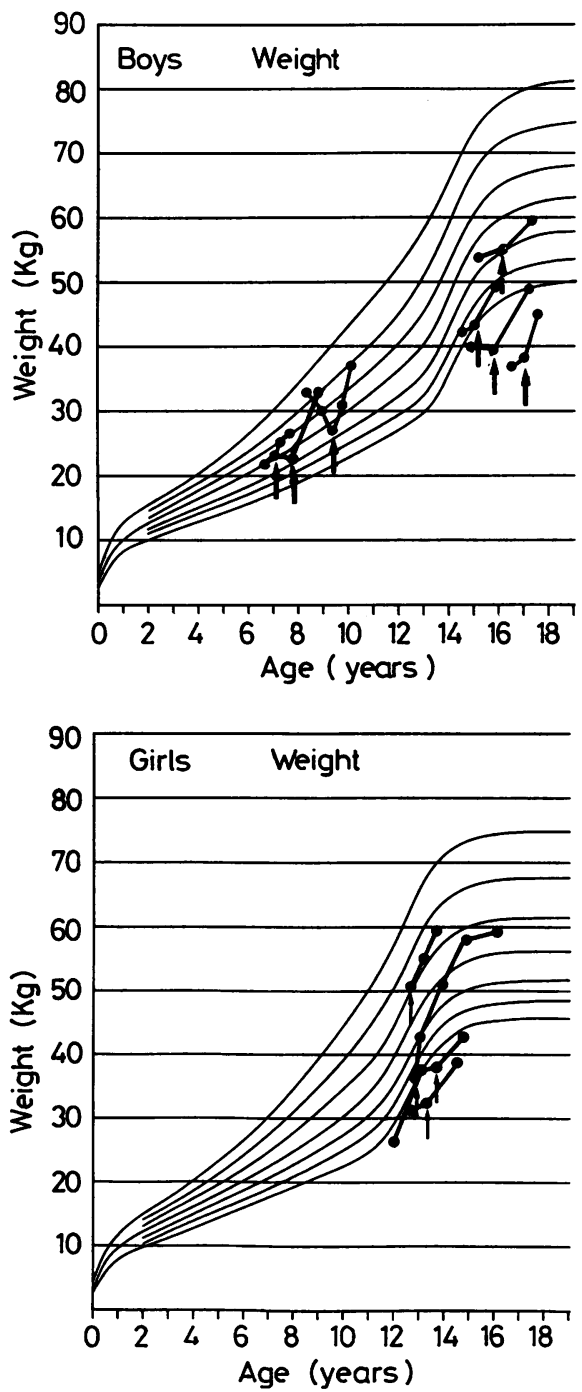
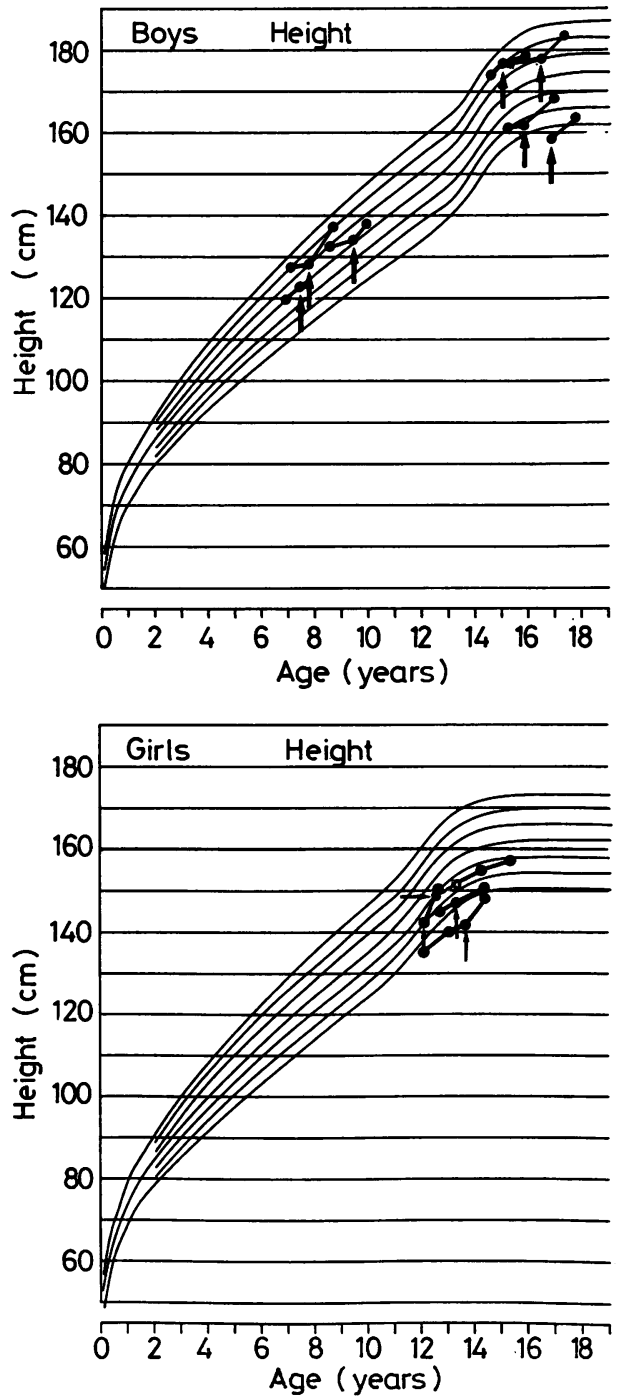

Fig. 2 Weight and height plotted on Tanner's tables. Arrows indicate start of treatment with an elemental diet. 


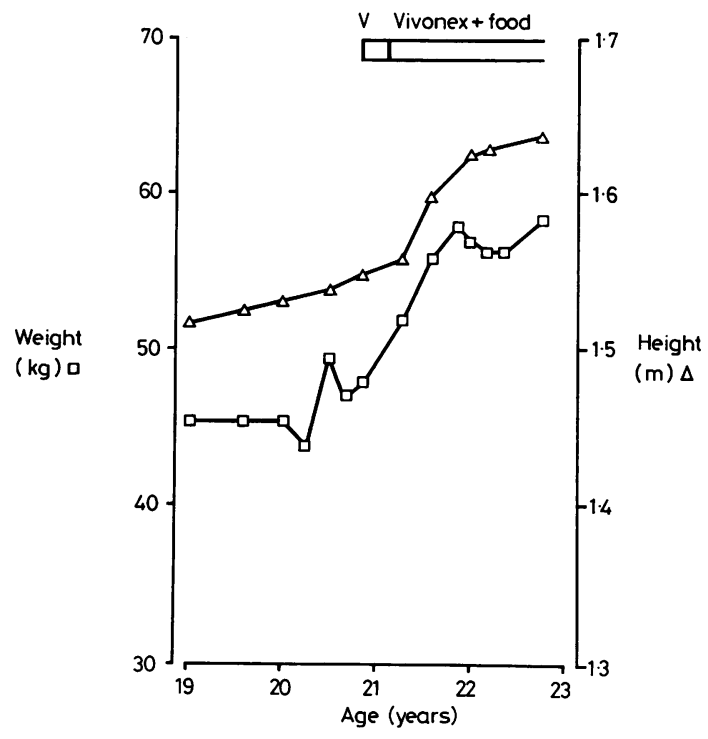

Fig. 3 A plot of weight and height of a 19-year-old boy with Crohn's disease who presented with delayed puberty. $V=$ indicates a period when Vivonex was the only form of treatment given.

disadvantages but most of our patients were able to tolerate it with encouragement of nursing and dietetic staff. The patients found the diet more acceptable if the symptoms improved. The diet was introduced gradually to avoid abdominal pain and bloating which can be caused by the hyperosmolar solution. Patients who experienced these symptoms were introduced to the diet more gradually.

Four patients were also treated with corticosteroids. The 2 receiving corticosteroids before the diet started had stunting of growth and one of them had collapsed vertebrae. One other patient still requires prednisolone $10 \mathrm{mg}$ a day as maintenance treatment. The two patients who started receiving corticosteroids with the elemental diet were given prednisolone $20 \mathrm{mg} /$ day which was reduced to $10 \mathrm{mg}$ on alternate days by the end of the 6 weeks. The diet may reduce the corticosteroid dose and duration of treatment and avoid stunting of growth.

These preliminary results although uncontrolled suggest that an elemental diet given orally is a simple, safe method of inducing a remission of Crohn's disease resulting in an alleviation of symptoms, an improved nutritional status, and a significant gain in height and weight.

We thank Ms Lycia Shortland and Ms Pat Hulme for their expert help in these studies.

\section{References}

${ }^{1}$ Summers R W, Switz D M, Sessions J T, Jr, et al. National
Cooperative Crohn's Disease Study: results of drug treatment. Gastroenterology 1979; 77: 847-69.

2 Whittington P F, Barnes H V, Bayless T M. Medical management of Crohn's disease in adolescence. Gastroenterology 1977; 72: 1338-44.

3 Grand R J, Homer D R. Approaches to inflammatory bowel disease in childhood and adolescence. Pediatr Clin North Am 1975; 22: 835-50.

4 O'Donoghue D P, Dawson A M. Crohn's disease in childhood. Arch Dis Child 1977; 52: 627-32.

5 Block G E, Moossa A R, Simonowitz D. The operative treatment of Crohn's disease in childhood. Surg Gynecol Obstet 1977; 144: 713-7.

- Harris G H, Hollabaugh R S, Clatworthy H W, Jr. Surgery for developmental and growth failure in childhood granulomatous enteritis. J Pediatr Surg 1974; 9: $301-4$.

7 Greenstein A J, Sachar D B, Pasternack B J, Janowitz H D. Reoperation and recurrence in Crohn's colitis and ileocolitis. N Engl J Med 1975 ; 293: 685-90.

8 Layden T, Rosenberg J, Nemchausky B, Elson C, Rosenberg I. Reversal of growth arrest in adolescents with Crohn's disease after parenteral alimentation. Gastroenterology 1976; 70: 1017-21.

9 Kelts D G, Grand R J, Shen G, Watkins J B, Werlin S L, Boehme C. Nutritional basis of growth failure in children and adolescents with Crohn's disease. Gastroenterology 1979; 76: 720-7.

10 Strobel C T, Byrne W J, Ament M E. Home parenteral nutrition in children with Crohn's disease, an effective management alternative. Gastroenterology 1979; 77: $272-9$.

11 O'Morain C, Segal A W, Levi A J. Elemental diets in treatment of acute Crohn's disease. $\mathrm{Br} \mathrm{Med} J$ 1980; 281 : 1173-5.

12 Axelsson C, Jarnum S. Assessment of the therapeutic value of an elemental diet in chronic inflammatory bowel disease. Scand J Gastroenterol 1977; 12: 89-95.

13 Ricour C, Duhamel J F, Nihoul-Fekete C. Utilisation de la nutrition parentérale élémentaire. Arch Fr Pediatr 1977; 34: 505-13.

14 Younoszai M K. Growth in a teenage boy with granulomatous enteritis fed elemental diets. Am $\mathrm{J}$ Dis Child $1977 ; 131: 235$.

15 Segal A W, Levi A J, Loewi G. Levamisole in the treatment of Crohn's disease. Lancet 1977; ii: 382-4.

16 Goode A, Hawkins T, Feggetter J G W, Johnston I D A. Use of an elemental diet for long term nutritional support in Crohn's disease. Lancet 1976; i: 122-4.

17 Morin C L, Roulet M, Roy C C, Weber A. Continuous elemental enteral alimentation in children with Crohn's disease and growth failure. Gastroenterology 1980; 79: 1205-10.

18 McArdle A H, Brown $R$ A, Echave V, Rivilis $J$, Thompson A G. Alterations in gastric and pancreatic secretion induced by the feeding of an elemental diet (abstract). Arch Fr Mal App Dig 1972; 61 : 115C.

19 Logan R F A, Gillon J, Ferrington C, Ferguson A. Reduction of gastrointestinal protein loss by elemental diet in Crohn's disease of the small bowel. Gut 1981; 22: 383-7.

Correspondence to Dr H B Valman, Department of Paediatrics, Northwick Park Hospital, Watford Road, Harrow, Middlesex HA1 3UJ.

Received 14 October 1982 